\title{
Novedades jurisprudenciales de la Suprema Corte de Justicia Bonaerense y la Corte Suprema de Justicia de Nación
}

Por Juan Francisco Díaz

\section{El límite en la cobertura del seguro automotor obligatorio es válido y oponible a terceros}

Así lo declaró la Corte Suprema de Justicia de la Nación, en el voto de la mayoría (Lorenzetti, Highton de Nolasco y Rosenkrantz), el máximo tribunal destacó que "no es posible imponer obligaciones a la aseguradora más allá de los términos pactados (...) la ley establece que el contrato es la fuente de sus obligaciones y en dicho instrumento se determinan los alcances y límites de la garantía debida". Además, sentenció que "obligar a la aseguradora a afrontar el pago de los daños sufridos por la víctima más allá del límite que emerge de la póliza, con el único argumento de la supuesta desnaturalización de la función social del seguro, implica una violación de su derecho de propiedad”.

CSJN "Flores, Lorena Romina c/ Giménez, Marcelino Osvaldo y otro si daños y perjuicios (acc. trán. cl les. o muerte)", del 6 de junio de 2017.

\section{La Corte estableció que el trabajador debe pagar las costas cuando el juicio lo pierde por su culpa}

El Máximo Tribunal estableció que cuando el trabajador pierde por su culpa un juicio laboral debe pagar los gastos en concepto de honorarios de los abogados y los peritos que hayan intervenido. La sentencia, que contó con los votos de los jueces Lorenzetti, Highton de Nolasco, Maqueda y Rosenkrantz, afirma que como el rechazo de la demandada se debió a la actitud renuente del trabajador, no había motivos válidos para apartarse de la regla legal que establece que quien pierde un juicio debe pagar los gastos por honorarios que ese juicio originó.

CSJN "López, Enrique Eduardo c/ Horizonte Compañia Argentina de Seguros Generales S.A. s/ accidente - ley especial", 4 de Julio de 2017. 


\section{El comprador de un inmueble cuya expropiación fue anterior a la adquisición no está legitimado a demandar}

Así lo afirmó la Suprema Corte bonaerense, con voto de los jueces de Lázzari, Kogan, Soria y Kohan, señalaron que el comprador de un inmueble no está legitimado para promover la expropiación inversa cuando la adquisición haya sido anterior al hecho que motivara el desmembramiento del dominio. La mayoría sostuvo que la acción expropiatoria es personal y no se transmite en forma automática. La minoría, integrada por Negri, Genoud y Pettigiani, consideró que el adquirente sí se encuentra legitimado a reclamar el resarcimiento.

SCJB "La Cassina S.A. contra Fisco de la Provincia de Buenos Aires. Expropiación inversa", C. 103.955, 28 de Junio de 2017.

\section{La Corte Suprema de Justicia de la Nación convalidó las elecciones del 2015 en la Provincia de Tucumán}

Así lo hizo el Máximo Tribunal al rechazar un recurso de queja del Frente Electoral Acuerdo del Bicentenario contra la decisión de la Corte Tucumana que dejó sin efecto la decisión de la Cámara Contencioso Administrativo que anulaba las elecciones del 23 de agosto del 2015, en las cuales, el candidato Juan Manzur fue electo gobernador, derrotando a José Cano.

CSJN "Recurso de hecho deducido por el actor en la causa Acuerdo para el Bicentenario c/ Provincia de Tucumán s/amparo", 11 de Julio de 2017

\section{La Corte dejó firme la decisión que ordena pagar jubilación de privilegio de camarista a un condenado por delitos de lesa humanidad}

El Máximo Tribunal rechazó un recurso de queja del Consejo de la Magistratura contra la decisión de la Sala II de la Cámara Federal de la Seguridad Social que admitió un amparo de Jaime Lamont Smart -primer civil condenado a reclusión perpetua por delitos de lesa humanidad-y ordenó que le abonen la jubilación como camarista por el hecho de haber integrado la Cámara Federal en lo Penal de la Nación, un tribunal creado por el gobierno de facto de Onganía para juzgar "delitos subversivos" que pasó a la historia como una comisión especial de las que prohíbe nuestra Constitución Nacional.

CSJN "Recurso de hecho deducido por la demandada en la causa Smart, Jaime Lamont c/ Consejo de la Magistratura s/ amparos y sumarisimos", 4 de julio de 2017 


\section{Una trabajadora que sufre un accidente laboral tiene derecho a una indemnización que compense totalmente la pérdida de su capacidad aunque no haya perdido su empleo}

Así lo afirmó, por mayoría, la Corte Suprema de Justicia de la Nación al revocar un fallo de la Suprema Corte de Justicia de Mendoza que había reducido a menos de cuatrocientos mil pesos -a valores de 2012- la indemnización por los graves daños provocados por el accidente de trabajo que Stella Maris Ontiveros sufrió en 2001 mientras cumplía funciones como magistrada de primera instancia en la justicia local.

Los Jueces Maqueda y Rosatti, en su voto conjunto, recordaron que el derecho a la reparación total encuentra su fundamento en la Constitución Nacional y en los tratados internacionales incorporados a ella, y que la integridad de la persona tanto en su aspecto físico como en el psíquico y el moral- tiene en sí misma un valor indemnizable. A partir de ello descalificaron el argumento dado por la corte provincial para reducir la indemnización referido a que la demandante continuó en sus funciones de jueza después del accidente, sin merma en su salario

CSJN "Recurso de hecho deducido por la actor a en la causa Ontiveros, Stella Maris c/ Prevención ARTS .A.Y otros s/ accidente- inc.y cas.", 10 de Agosto de 2017.

\section{La Corte bonaerense estableció pautas para determinar el monto de la cuota alimentaria}

La Suprema Corte de Justicia de la Provincia de Buenos Aires determinó pautas para la cuantificación de la cuota alimentaria teniendo en consideración las crecientes necesidades de los niños según su edad y la relación con las posibilidades y modo de vida del alimentante. El Máximo Tribunal consignó que para fijar la cuota se debe tener en cuanta las "reales necesidades de los niños en su relación con su edad y calidad de vida a la que acceden, posibilidades del alimentante y aumento del costo de vida".

SCJB C. 120.884, "D., M. contra G., P. J.. Alimentos", 7 de Junio de 2017.

\section{La Corte Suprema dejó sin efecto la decisión que impedía a Carlos Menem ser candidato a Senador Nacional por La Rioja}

El Máximo Tribunal descalificó la sentencia de la Cámara Electoral dado que ésta no analizó el planteo relacionado con la legitimación, es decir, si alguien que no es de la lista puede impugnarla en las elecciones primarias. Tampoco examinó la denominada "preclusión", es decir, si había vencido el plazo para la impugnación, cuestión que ha sido muy importante en la jurisprudencia del alto tribunal para dar seguridad jurídica. De esta manera afectó los derechos de quienes invocaron defensas en el proceso. La Corte, no obstante, no se pronunció sobre el 
fondo que es si Menem puede ser candidato, aspecto que puede generar un nuevo pronunciamiento antes de las elecciones.

CSJN "Acosta, Leonel Ignacio s/ impugnación de precandidatos elecciones primarias Frente Justicialista Riojano", 22 de Agosto de 2017

\section{Las Cataratas del Iguazú pertenecen al dominio público del Estado Nacional}

Así lo determinó la Corte Suprema de Justicia de la Nación al admitir una demanda de la Administración de Parques Nacionales y declarar la inconstitucionalidad de dos leyes de la Provincia de Misiones que creaban el Parque Provincial Río Iguazú en un espacio geográfico que, según determinó el Tribunal, corresponde al Parque Nacional Iguazú. Los jueces fundaron su decisión en que previamente a la creación de la Provincia de Misiones (1954) fue establecido el Parque Nacional Iguazú (1934) y su motivo principal fue, justamente, el fenómeno natural de las Cataratas que se hallan en su territorio.

CSJN "Administración de Parques Nacionales c/ Misiones, Provincia de s/ acción declarativa de inconstitucionalidad", 10 de Agosto de 2017

\section{La información sobre asuntos públicos también están amparados por la doctrina de la real malicia}

El máximo tribunal admitió una queja y dejó sin efecto la condena contra los periodistas María Laura Santillan, Juan Micelli y Arte Radiotelevisivo Argentino S.A. con motivo de la emisión en el programa "Telenoche Investiga" de un informe sobre la compañía Boston Medical Group que la firma consideró lesivo de su prestigio comercial. La Corte consideró que al tratarse de un informe vinculado con la salud pública y las características del sujeto argaviado, resultaba la aplicación de la doctrina de la real malicia y, en tal caso, no correspondía la condena a los periodistas y a la productora.

CSJN "Recurso de hecho deducido por la parte demandada en la causa Boston Medical Group S.A. c/ Arte Radiotelevisivo Argentino S.A. y otros s/ daños y perjuicios", 29 de Agosto de 2017

\section{La actividad de los buscadores de internet se encuentra amparada por la libertad de expresión}

Así lo afirmó hoy la Corte Suprema de Justicia de la Nación al reafirmar la doctrina del fallo "Rodríguez, María Belén". En tal sentido, el máximo tribunal destacó que los buscadores son meros intermediarios que se limitan a mostrar contenidos ajenos (exhibidos en otras páginas web) y que su responsabilidad surge 
-en supuestos excepcionales- cuando no actuaran diligentemente a partir del efectivo conocimiento de la ilicitud de dichos contenidos.

CSJN "Gimbutas, Carolina Valeria c/ Google Inc. s/ daños y perjuicios", 12 de Septiembre de 2017

\section{La Corte rechazó la reintegrar gastos de cobertura de la obra social a un menor por no haber presentado el certificado de discapacidad}

El máximo tribunal eximió a la Obra Social del Poder Judicial de la Nación de cubrir los gastos de un menor con discapacidad por no haber acompañado el certificado que así lo acreditara, extendido por el Ministerio de Salud de la Nación o por "el organismo competente establecido en las leyes provinciales". Se trató del caso por el cual los padres del menor le pedían a la OSPJN el reintegro de gastos y el daño moral. La Justicia Federal de Posadas había admitido el reclamo y subrayado que "el organismo conocía el estado de salud del menor".

CSJN A., M. G. c/ Obra Social del Poder Judicial de la Nación s/ cobro de pesos/ sumas de dinero", 5 de Septiembre de 2017

\section{Los jueces laborales no pueden aumentar a su arbitrio la indemnización de accidentes de trabajo fijada legalmente}

Así lo afirmó la Corte Suprema al dejar sin efecto una sentencia de la Sala VII de la Cámara Nacional del Trabajo que, sin declarar inconstitucional la ley de ART que fija los resarcimientos y dejando de lado un precedente del máximo tribunal con invocaciones a principios genéricos vinculados con la equidad de la reparación, incrementó el monto de una indemnización por accidente laboral. La Corte descalificó la decisión por arbitraria al apartarse injustificadamente de la ley aplicable.

CSJN "Recurso de hecho deducido por la demandada en la causa Marando, Catalina Graciela c/ QBE Argentina ART S.A. s/ accidente- ley especial", 12 de Septiembre de 2017

\section{Espiar el Facebook, mail o celular de una pareja es un delito federal}

Así lo determinó la Corte Suprema de Justicia de la Nación al definir, por remisión al dictamen del procurador Eduardo Ezequiel Casal, una cuestión de competencia en una causa iniciada por una mujer dado que "su ex pareja habría ingresado a su usuario de la red social Facebook y en su correo electrónico gratuito, y además habría obtenido, presumiblemente, los datos de sus contactos del teléfono celular y copiado su tarjeta SIM". La Corte determinó "el usuario de la 
red social y el correo electrónico constituyen una comunicación electrónica o dato informático de acceso restringido, cuyo acceso sólo es posible a través de un medio que por sus características propias se encuentra dentro de los servicios de telecomunicaciones que son de interés de la Nación".

CSJN "T. G. W. s/ violación sistema informático (art. 153 bis, 1er párr del C.P.)", 19 de Septiembre de 2017 